\title{
The Deformation Behaviors and Mechanism of the High- Temperature Mechanical Properties of a Ni48W35Co17 Alloy
}

\author{
Guoliang Xie ${ }^{1}$, Wenli Xue ${ }^{1}$, Yilei Fu ${ }^{2}$, Kai Feng ${ }^{1}$, Rui Wang ${ }^{2}$ and Lei Zheng ${ }^{3, *}$ \\ 1 State Key Laboratory for Advanced Metals and Materials, University of Science and Technology Beijing, \\ Beijing 100083, China; leon_xq@126.com (G.X.); g20199201@xs.ustb.edu.cn (W.X.); \\ g20199184@xs.ustb.edu.cn (K.F.) \\ 2 Beijing Laboratory of Metallic Materials and Processing for Modern Transportation, University of Science and \\ Technology Beijing, Beijing 100083, China; s20191347@xs.ustb.edu.cn (Y.F.); s20181359@xs.ustb.edu.cn (R.W.) \\ 3 School of Materials Science and Engineering, University of Science and Technology Beijing, Beijing 100083, China \\ * Correspondence: zhenglei@ustb.edu.cn
}

Citation: Xie, G.; Xue, W.; Fu, Y.; Feng, K.; Wang, R.; Zheng, L. The Deformation Behaviors and Mechanism of the High-Temperature Mechanical Properties of a Ni48W35Co17 Alloy. Metals 2021, 11, 1755. https://doi.org/10.3390/ met11111755

Academic Editor: Tilmann Beck

Received: 13 August 2021

Accepted: 25 October 2021

Published: 1 November 2021

Publisher's Note: MDPI stays neutral with regard to jurisdictional claims in published maps and institutional affiliations.

Copyright: (c) 2021 by the authors. Licensee MDPI, Basel, Switzerland. This article is an open access article distributed under the terms and conditions of the Creative Commons Attribution (CC BY) license (https:// creativecommons.org/licenses/by/ $4.0 /)$.

\begin{abstract}
Investigations of the plastic deformation mechanisms of Ni-W-based heavy alloys varying with increasing temperatures are very important for the development of hot forming processes and applications at elevated temperatures. In this study, the continuous variation of strength and plasticity of a novel Ni-W-based heavy alloy with increasing temperatures was investigated. The tensile strength of a Ni48W35Co17 sample at $600{ }^{\circ} \mathrm{C}$ was $471 \mathrm{MPa}$, which was $47 \%$ lower than that at $100{ }^{\circ} \mathrm{C}$. A variation in an abnormal decrease in elongations at temperatures from $400{ }^{\circ} \mathrm{C}$ to $800{ }^{\circ} \mathrm{C}$ was found in this alloy. The elongation rate of the sample tensile at $600{ }^{\circ} \mathrm{C}$ was $19 \%$, which was $73 \%$ lower than that at $100{ }^{\circ} \mathrm{C}$. A microstructural analysis revealed that the number of twins in the sample tensile at a temperature higher than $600^{\circ} \mathrm{C}$ increased considerably compared with the sample tensile at lower temperatures, indicating that the dislocation slips were suppressed during the high-temperature stretching process. The precipitates of the $\mathrm{NiW}$ phase were found in the $600{ }^{\circ} \mathrm{C}$ tensile sample, which was not clearly observed in the $400{ }^{\circ} \mathrm{C}$ tensile sample, suggesting that dislocation slips were affected by the formation of these precipitates. Moreover, the orientation relationship between the matrix and NiW phase was $(200) \mathrm{Ni} / /(240) \mathrm{NiW}$ and [001]Ni//[001]NiW. The tiny precipitated phase was the main reason for the plasticity decrease of the alloy with the temperature increase.
\end{abstract}

Keywords: heavy alloy; Ni-W-based alloy; high-temperature mechanical properties; microstructure; strengthening mechanisms

\section{Introduction}

Heavy alloys have been widely applied in aerospace, aviation, military, and nuclear fields due to their high mechanical properties, good oxidation resistance, high damping behavior, and excellent fatigue performance [1-5]. Traditional high heavy alloys mainly include ultrahigh-strength steel and high-density tungsten alloys [6-8]. High-strength steels have been widely used in the aerospace and military fields due to their excellent properties. However, these crystals have 48 slip systems, due to the mostly body-centered cubic structure in high-strength steels, which makes it difficult for ultrahigh-strength steels to obtain higher penetration capabilities and makes them prone to adiabatic shear fracture $[9,10]$. High-density tungsten alloys show better properties than high-strength steel, such as high density, high damping, and good corrosion resistance. Nevertheless, the impact toughness of tungsten alloys is low due to the inherent weakness deformability of tungsten at room temperature, which is prone to fracture and failure [11-13]. Ni-W-based face-centered cubic alloys are newly developed heavy alloys that have attracted attention recently $[5,14,15]$. These alloys not only have high density but also have high strength and good plasticity. Moreover, Ni-W-based alloys are deformable and heat treatable. Therefore, 
their overall mechanical strength and dynamic performance can be further enhanced through microstructural tailoring via work hardening and aging treatment.

The mechanical properties, rheological properties, and strengthening mechanisms of some Ni-W-based alloys have been studied. Based on available knowledge, increasing the content of $\mathrm{Ni}$ in W-based heavy alloys will help improve their toughness, as reported by German et al. [16]. Liu et al. [15] found that the structure and properties of NiW750 alloys are affected by aging treatment. The tensile strength of the NiW750 alloy can reach $1746 \mathrm{MPa}$ after aging at $750{ }^{\circ} \mathrm{C}$ for $5 \mathrm{~h}$. The nanosized $\mathrm{Ni}_{4} \mathrm{~W}$ precipitated phase is the main reason for the strength increase of the NiW750 alloy after aging. Li et al. [8] developed a medium-heavy alloy Ni-37W-5Co-1Ta. The tensile strength $(\mathrm{Rm})$ and proof strength $\left(\mathrm{Rp}_{0.2}\right)$ of the aged Ni-37W-5Co-1Ta alloy are approximately 1527 and $1337 \mathrm{MPa}$, respectively. In addition, the alloy has excellent impact toughness and dynamic properties, and the impact toughness of the forged alloy is $180 \mathrm{~J}$.

Existing studies on Ni-W-based alloys mainly analyze their room temperature performance and strengthening mechanism. The high-temperature mechanical properties of Ni-W-based alloys with high density and the corresponding mechanism of action are still vague. In particular, the possible short-range order phase and the corresponding influence of the precipitates on the mechanism of high-temperature strength and plasticity are required for further exploration. The variation in plastic and deformation behaviors at elevated temperatures will be very important for the hot forming process and applications of this alloy. Therefore, in this article, the high-temperature mechanical properties and strengthening mechanism of a novel $\mathrm{Ni}$-W-based heavy alloy $\left(\mathrm{Ni}_{48} \mathrm{~W}_{35} \mathrm{Co}_{17}\right.$ alloy) are investigated. The investigation of the precipitation process on the high-temperature mechanical properties is performed using a Gleeble 8100 thermal deformation simulation testing machine. Samples obtained by stretching at different temperatures were observed by scanning electron microscopy (SEM), electron backscattered diffraction (EBSD), and transmission electron microscopy (TEM). Finally, the high-temperature mechanical properties and strengthening mechanisms are discussed to provide a theoretical direction for the optimization of this alloy.

\section{Experimental Procedure}

$\mathrm{Ni}_{48} \mathrm{~W}_{35} \mathrm{Co}_{17}$ (mass fraction, \%) alloys were prepared using pure $\mathrm{Ni}, \mathrm{W}$, and Co master alloys in a magnetic suspension vacuum arc-melting furnace under a vacuum degree of $10^{4} \mathrm{~Pa}$. Air cooling treatment was used after melting, and the temperature decreased by $3-5{ }^{\circ} \mathrm{C}$ every $2 \mathrm{~s}$. Then, the as-cast alloys were forged two times at approximately $1200^{\circ} \mathrm{C}$, and finally, $\mathrm{Ni}_{48} \mathrm{~W}_{35} \mathrm{Co}_{17}$ bars with a $20 \mathrm{~mm}$ diameter were obtained.

The investigation of the precipitation process of the high-temperature mechanical properties was conducted using a Gleeble8100 thermal deformation simulation testing machine (DSI, Minnesota St. Paul, MN, USA). In a quasi-static tensile test, the strain rate was $5 \times 10^{-4} \mathrm{~s}^{-1}$. The tests were repeated for three times under each condition, to minimize the experimental errors.

Samples for SEM were first ground, polished, and etched in a mixed solution containing $35 \mathrm{~g} \mathrm{FeCl}_{3}+100 \mathrm{~mL} \mathrm{HCl}+40 \mathrm{~mL} \mathrm{C}_{2} \mathrm{H}_{5} \mathrm{OH}+10 \mathrm{~mL} \mathrm{HF}+40 \mathrm{~mL} \mathrm{H}_{2} \mathrm{O}$. Samples for EBSD were electrolytically polished to remove the surface stress to ensure a high calibration rate. The electrolytic polishing solution contained $10 \mathrm{~g} \mathrm{CuCl}_{2}+200 \mathrm{~mL} \mathrm{HCl}+200 \mathrm{~mL}$ $\mathrm{C}_{2} \mathrm{H}_{5} \mathrm{OH}$. Samples for TEM observations were prepared via a focused ion beam with a size range of 30-60 nm, which was beneficial for TEM observation. The microstructures of the samples were observed via SEM (JEOL-7900F field emission scanning electron microscope, JEOL., Tokyo, Japan), EBSD (NordlysMax3, Oxford Instruments, Shanghai, China), and TEM (Tecnai G² F20 transmission electron microscope, FEI, Hillsboro, OR, USA). 


\section{Results}

\subsection{Tensile Properties of the Ni48W35Co17 Alloy at Different Temperatures}

Quasi-static tensile samples were all prepared from forged $\mathrm{Ni}_{48} \mathrm{~W}_{35} \mathrm{Co}_{17}$ alloys. The quasi-static tensile properties of the $\mathrm{Ni}_{48} \mathrm{~W}_{35} \mathrm{Co}_{17}$ alloy at different temperatures are shown in Figure 1, and the specific data is shown in the Table 1. The tensile strength of the samples decreases as the temperature increases. The tensile strength of the samples decreases at a slower rate with the temperature increase when the temperature is less than $400{ }^{\circ} \mathrm{C}$. The tensile strength of a sample tensile at $400{ }^{\circ} \mathrm{C}$ is $765 \mathrm{MPa}$, which is only $13 \%$ lower than that at $100{ }^{\circ} \mathrm{C}$; the tensile strength of the samples decreases at a slower rate with the increases in temperature when the temperature is higher than $600^{\circ} \mathrm{C}$. The tensile strength of the sample tensile at $600{ }^{\circ} \mathrm{C}$ is $471 \mathrm{MPa}$, which is $47 \%$ lower than that at $100{ }^{\circ} \mathrm{C}$. The plasticity of the samples is also affected by temperature. The plasticity of the samples slightly changes with the stretching temperature when the temperature is less than $400^{\circ} \mathrm{C}$. The elongation of the samples is $68 \%$ at $400{ }^{\circ} \mathrm{C}$, which is only $4 \%$ lower than that at $100{ }^{\circ} \mathrm{C}$. The plasticity of the samples decreases as the temperature increases at a faster rate when the stretching temperature is higher than $600{ }^{\circ} \mathrm{C}$. The elongation rate is $19 \%$ when the stretching temperature is $600{ }^{\circ} \mathrm{C}$, which is $73 \%$ lower than that at $100{ }^{\circ} \mathrm{C}$.

(a)

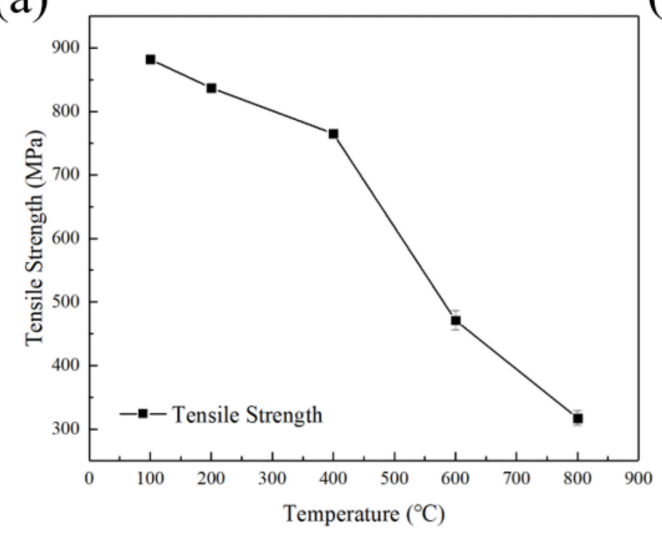

(b)

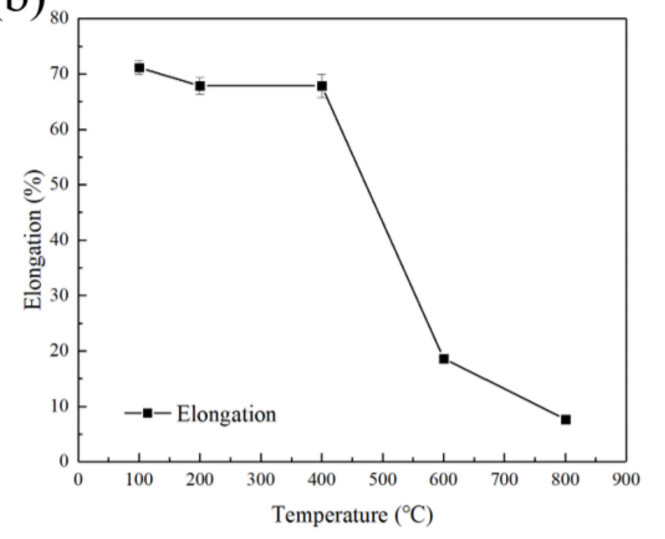

Figure 1. Quasi-static tensile properties of Ni48W35Co17 alloy at different temperatures, (a) the tensile strength; (b) the elongation.

Table 1. Quasi-static tensile properties of Ni48W35Co17 alloy at different temperatures.

\begin{tabular}{ccc}
\hline Temperature $\left({ }^{\circ} \mathbf{C}\right)$ & Tensile Strength (Mpa) & Elongation (\%) \\
\hline 100 & 882 & 71.2 \\
200 & 837 & 67.8 \\
400 & 765 & 67.8 \\
600 & 471 & 18.7 \\
800 & 317 & 7.7 \\
\hline
\end{tabular}

These results indicate that the strength and plasticity of the samples are affected by temperature. The strength of most metal samples decreases as the temperature increases, and the plasticity increases as the temperature increases [13]. However, the strength and plasticity of the $\mathrm{Ni}_{48} \mathrm{~W}_{35} \mathrm{Co}_{17}$ sample both decrease as the temperature increases, which differs from the trend of ordinary metal samples. These changes in strength and plasticity are due to the evolution of the microstructure, which will be analyzed in the following discussion section. The strength and plasticity of the sample are still at a high level at $400{ }^{\circ} \mathrm{C}$, but the strength and plasticity at $600^{\circ} \mathrm{C}$ are dramatically reduced compared with those at $400{ }^{\circ} \mathrm{C}$. Unlike most FCC structured metallic materials, the elongation of this alloy is decreased in the temperature range from $400{ }^{\circ} \mathrm{C}$ to $800^{\circ} \mathrm{C}$. The elongation of the alloys is reduced to $19 \%$ at $600{ }^{\circ} \mathrm{C}$ and less than $10 \%$ at $800{ }^{\circ} \mathrm{C}$, suggesting that the deformation mechanism is changed. 


\subsection{Microstructure of Sample Tensile at Different Temperatures}

The microstructures of the samples tested at different temperatures are demonstrated in the SEM micrographs shown in Figure 2. Numerous deformed grains and slip bands are observed in the sample obtained by tensile testing at room temperature (Figure 2a), with excellent plasticity, suggesting that the dislocation can move through slip and cross slip. The deformed grains and slip bands can also be observed in the samples obtained by tensile tests at $100^{\circ} \mathrm{C}, 200{ }^{\circ} \mathrm{C}$, and $400{ }^{\circ} \mathrm{C}$ (Figure $2 \mathrm{~b}-\mathrm{d}$ ), which indicates that the dislocation slip ability of the alloy is still good when it is tested at a temperature of less than $400^{\circ} \mathrm{C}$. Regular-shaped crystal grains are observed in the samples obtained by stretching at $600{ }^{\circ} \mathrm{C}$ and $800{ }^{\circ} \mathrm{C}$, with a very small number of slip bands observed in the samples (Figure 2e,f), showing that the slip of the dislocation in the sample tested at high temperatures is hindered and the samples exhibit poor plasticity.
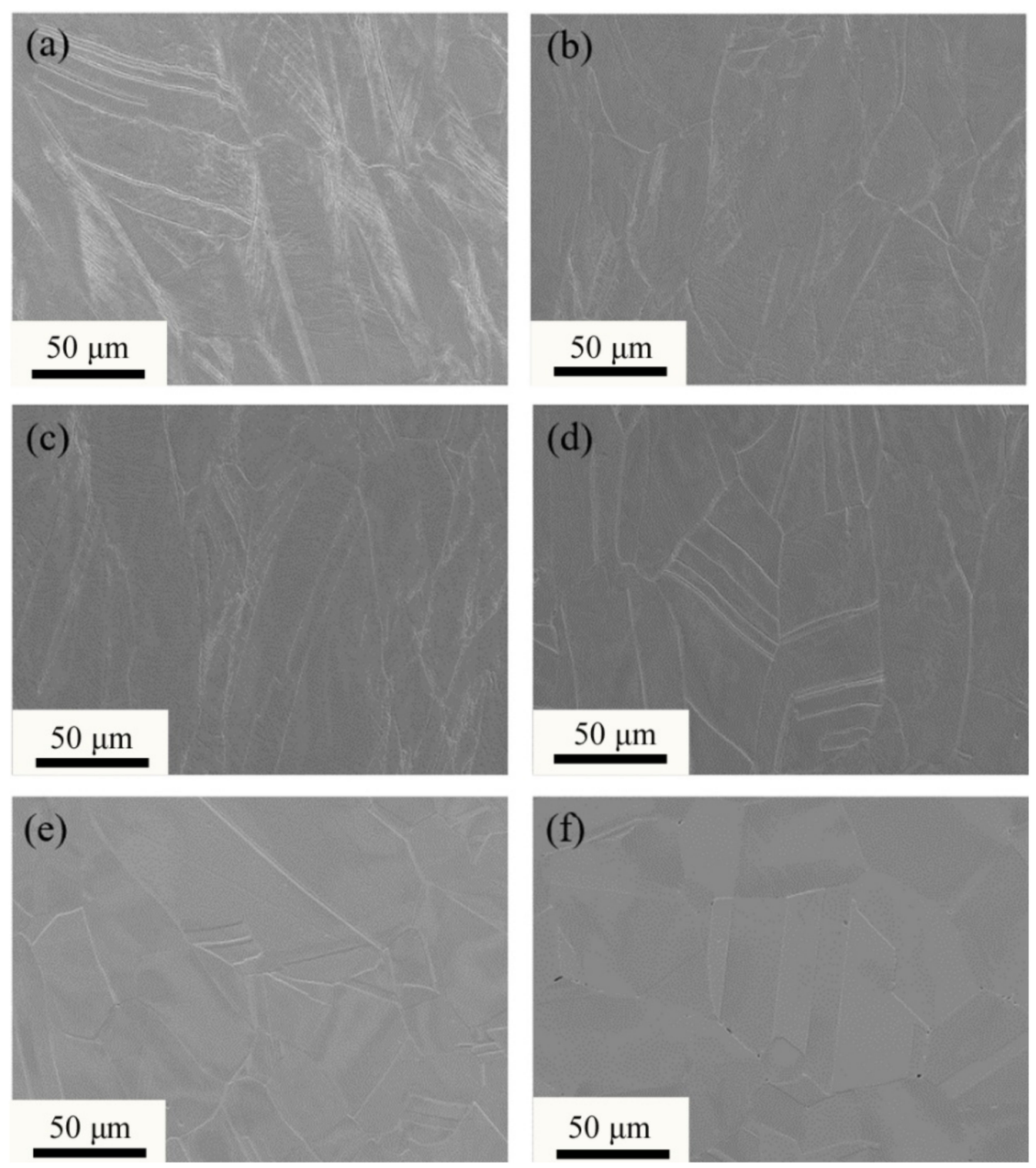

Figure 2. SEM micrographs of samples obtained by stretching at different temperatures: (a) room temperature, (b) $100{ }^{\circ} \mathrm{C}$, (c) $200{ }^{\circ} \mathrm{C}$, (d) $400{ }^{\circ} \mathrm{C}$, (e) $600{ }^{\circ} \mathrm{C}$, and (f) $800{ }^{\circ} \mathrm{C}$.

The microstructures and orientations of the samples were further analyzed by EBSD, the results of which are shown in Figure 3. The grain shape of the room-temperature-tensile sample is irregular, and the number of twins is minute in the sample, as seen in Figure 3a. In addition, the crystal grains of the room-temperature-tensile sample have a certain preferred 
orientation, which can be found by analyzing the pole figures, as shown in Figure $3 \mathrm{~b}$. The IPF diagram of the $400{ }^{\circ} \mathrm{C}$ tensile sample is similar to that of the room-temperature tensile samples. The crystal grains are also irregular, and the proportion of twins is minute, as seen in Figure 3c. Similarly, the grains in the $400{ }^{\circ} \mathrm{C}$ tensile sample also exhibit a preferred orientation, as seen in Figure $3 \mathrm{~d}$. The grains of the $600{ }^{\circ} \mathrm{C}$ tensile sample are regular, containing a large ratio of twins, as seen in Figure $3 \mathrm{e}$, which is different from that of the sample tested at $400{ }^{\circ} \mathrm{C}$. From the pole figures in Figure 3, the crystal grains of the $600{ }^{\circ} \mathrm{C}$ tensile sample show no obvious preferred orientation. In addition, many symmetrically distributed orientations can be observed in the pole figures, which indicate numerous twins in the sample.

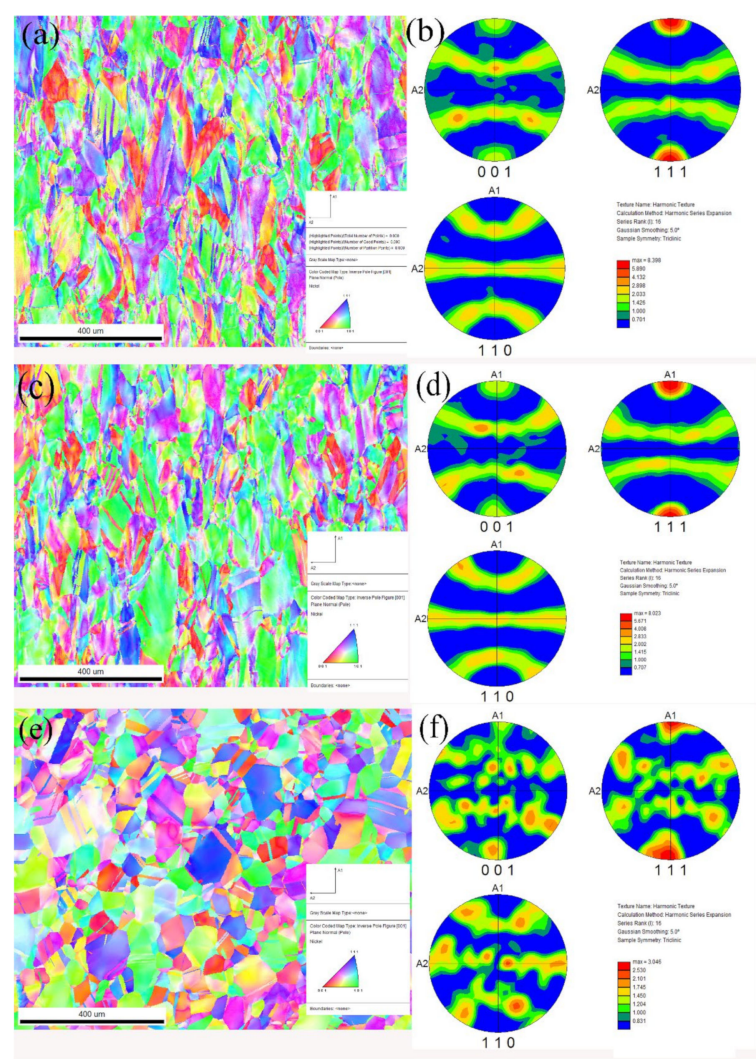

Figure 3. IPF and PF of samples obtained by stretching at different temperatures: (a) IPF, room temperature, (b) PF, room temperature, (c) $\mathrm{IPF}, 400{ }^{\circ} \mathrm{C}$, (d) $\mathrm{PF}, 400{ }^{\circ} \mathrm{C}$, (e) $\mathrm{IPF}, 600{ }^{\circ} \mathrm{C}$, and (f) $\mathrm{PF}$, $600^{\circ} \mathrm{C}$.

The microstructure of the tensile samples at temperatures lower than $400^{\circ} \mathrm{C}$ is roughly the same when combining the SEM and EBSD results. The microstructure of the sample at $600{ }^{\circ} \mathrm{C}$ changes significantly more than that of the tensile samples below $400{ }^{\circ} \mathrm{C}$. The slip bands cannot be observed, and the number of twins is large in the $600{ }^{\circ} \mathrm{C}$ tensile sample. The microstructure agrees well with the quasi-static tensile properties results. The reasons for the sudden changes in plasticity and strength of high-temperature tensile samples will be further analyzed in the following discussion section.

\subsection{TEM Analyses of the Deformation Areas of Sample Tensile at Different Temperatures}

The TEM micrographs and the corresponding selected area electron diffraction (SAED) patterns of the samples obtained from sample tested at $400{ }^{\circ} \mathrm{C}$ and $600{ }^{\circ} \mathrm{C}$ are shown in Figure 4 to analyze the detailed deformation behaviors. Numerous dislocations move along a specific orientation, as shown in Figure 4a. In addition, obvious precipitation cannot be found in the $400{ }^{\circ} \mathrm{C}$ tensile sample, which can be confirmed by the SAED patterns in Figure $4 \mathrm{~b}$. No obvious diffraction spots other than the matrix diffraction spots 
can be observed in the SAED patterns, as shown in Figure $4 \mathrm{~b}$. However, numerous tiny precipitates can be found in the tensile sample at $600^{\circ} \mathrm{C}$. It is also found that the number of slip bands is drastically reduced compared with the sample tested at $400{ }^{\circ} \mathrm{C}$, as shown in Figure 4c. The diffraction patterns of the NiW phase are shown in Figure 4d, which is similar to some previous work [5,14-17]. The orientation relationship between the matrix and $\mathrm{NiW}$ phase is $(200)_{\mathrm{Ni}} / /(240)_{\mathrm{NiW}}$ and [001]Ni//[001 $]_{\mathrm{NiW}}$. The impact of the NiW phase on the properties will be discussed in the following discussion section.
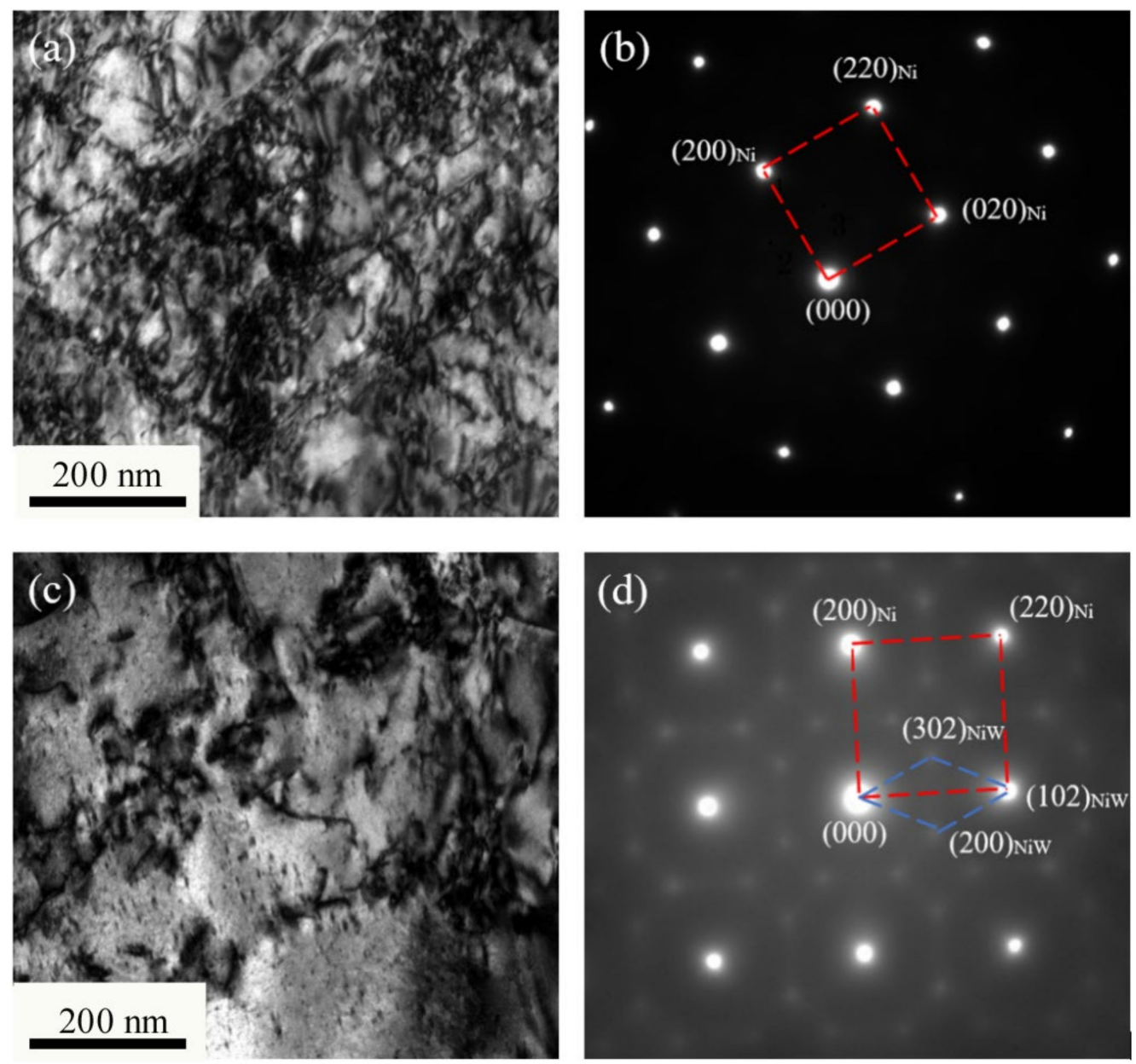

Figure 4. TEM micrographs and [001]Ni SAED patterns of the samples obtained by stretching at $400{ }^{\circ} \mathrm{C}(\mathbf{a}, \mathbf{b})$ and $600{ }^{\circ} \mathrm{C}(\mathbf{c}, \mathbf{d})$.

\section{Discussion}

\subsection{Variation in Microstructures and Properties at Elevated Temperatures}

From the results shown above, the strength and plasticity of the Ni48W35Co17 alloy continuously decrease as the temperature increases, which is different from the tendency of ordinary metal samples. These changes in strength and plasticity are due to the evolution of the microstructure $[18,19]$. The strength and plasticity of the sample at $400{ }^{\circ} \mathrm{C}$ are still at a high level, i.e., the tensile strength is $765 \mathrm{MPa}$, and the elongation is $68 \%$. The tensile strength of the sample at $600{ }^{\circ} \mathrm{C}$ is $471 \mathrm{MPa}$, which is $38 \%$ lower than that at $400{ }^{\circ} \mathrm{C}$. The elongation rate of the sample at $600{ }^{\circ} \mathrm{C}$ is $19 \%$, which is $72 \%$ lower than that at $400{ }^{\circ} \mathrm{C}$.

According to the above results, the microstructure of the tensile samples at different temperatures can be identified. Numerous tiny precipitates can be found in the $600{ }^{\circ} \mathrm{C}$ tensile sample, which cannot be obviously observed in the $400{ }^{\circ} \mathrm{C}$ tensile sample, as revealed in Figure 5a,b. The precipitated phase can hinder the movement of dislocations, consequently making it difficult for dislocations to slip, as shown in Figure $5 b$, which might be the reason why the number of slip bands in the tensile state of the $600{ }^{\circ} \mathrm{C}$ tensile sample 
drastically decreases compared with that of the tensile state of the $400{ }^{\circ} \mathrm{C}$ tensile sample. These tiny NiW precipitates might be one of the reasons for the poor plasticity of the $600{ }^{\circ} \mathrm{C}$ tensile sample. These brittle and hard intermetallic compounds at the grain boundaries tend to form stress concentrations at the grain boundaries during stretching, which leads to cracks and consequently to a decrease in the plasticity of the alloy, as has been widely accepted in other studies $[1,3,8,11-13]$. In addition, the grain boundaries of the $600{ }^{\circ} \mathrm{C}$ tensile sample differ from those of the $400{ }^{\circ} \mathrm{C}$ tensile sample. A number of $\mathrm{NiW}$ precipitates are formed in the grain boundary areas, as revealed in Figure $5 d$, which may prevent the dislocations from slipping across the grain boundaries. There are stacking faults near the grain boundary of the $600{ }^{\circ} \mathrm{C}$ tensile sample, which might be another reason for the poor plasticity of the $600{ }^{\circ} \mathrm{C}$ tensile sample, as seen in Figure 5c.
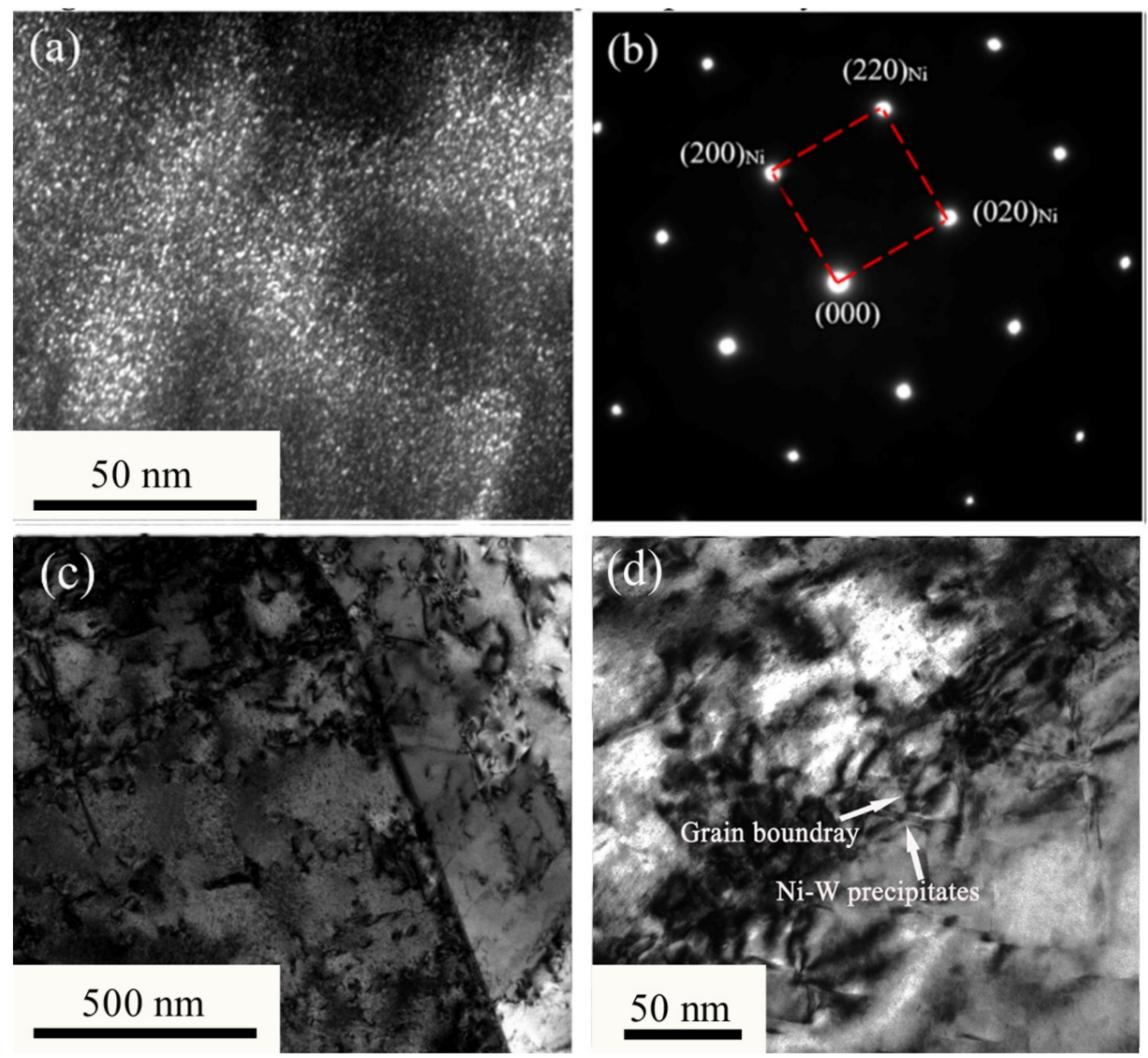

Figure 5. TEM micrographs of the samples obtained by stretching at $600{ }^{\circ} \mathrm{C}$ : (a) dark-field image of the NiW phase, (b) [001]Ni SAED pattern of the sample, (c) TEM micrograph of the sample, (d) NiW phase near the grain boundary.

The influence of NiW precipitates on plasticity can also be deduced and proved by the fractography of fracture surfaces of tensiled specimen, as seen in Figure 6. It can be seen that very different fractography of the fracture surfaces corresponding to the specimen tensiled at $400{ }^{\circ} \mathrm{C}$ and $600{ }^{\circ} \mathrm{C}$ are found by comparing Figure $6 a, b$. There are many small dimples and the fracture surface is very cliffy as shown in Figure 6a, suggesting the excellent plasticity at $400{ }^{\circ} \mathrm{C}$. The amount of dimples are found decreased in the tensile fracture fractography of specimen tensiled at $600^{\circ} \mathrm{C}$, as seen in Figure $6 \mathrm{~b}$. It shall also be noticed that there are obvious cracks along the grain boundaries are found in Figure $6 \mathrm{~b}$. It can be suggested by the comparison of Figure $6 \mathrm{a}, \mathrm{b}$ that the features of transcrystalline rupture are observed in Figure $6 a$, whereas the features of intercrystalline rupture are 
observed in Figure $6 \mathrm{~b}$. Therefore, it is reasonable to deduce that the NiW precipitates with much lower plasticity than matrix which are found distributed at the grain boundaries as observed by TEM in Figure 4, can cause the stress concentration during the tensile process and the consequent intercrystalline fracture [11-13] of the specimen. Thus, the plasticity of the specimen can be decreased at $600{ }^{\circ} \mathrm{C}$.

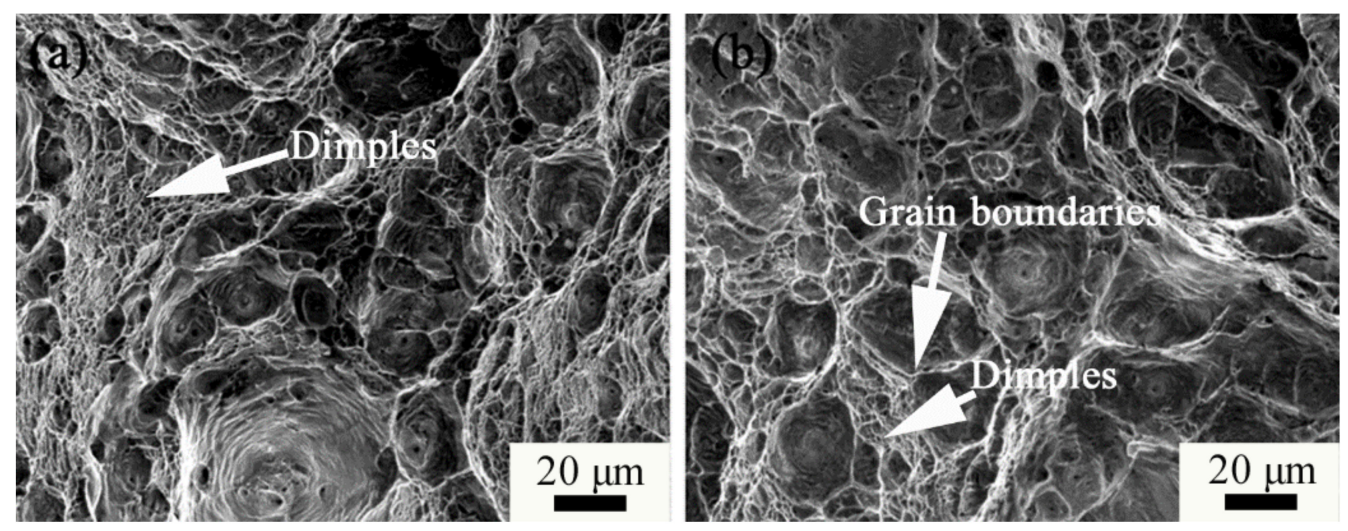

Figure 6. The fractography obtained by SEM of the samples tensiled at (a) $400{ }^{\circ} \mathrm{C},(\mathbf{b}) 600{ }^{\circ} \mathrm{C}$.

The grains in the $400{ }^{\circ} \mathrm{C}$ tensile sample are elongated and severely deformed, whereas the grains in the $600{ }^{\circ} \mathrm{C}$ tensile sample are insignificantly deformed, which confirms that the high-temperature plasticity of the $\mathrm{Ni}_{48} \mathrm{~W}_{35} \mathrm{Co}_{17}$ alloy samples is poor. From the SEM and EBSD results, the number of twins in the $600{ }^{\circ} \mathrm{C}$ tensile sample is greater than that in the $400{ }^{\circ} \mathrm{C}$ tensile sample, as seen in Figure $7 \mathrm{a}, \mathrm{b}$. The results show that the tensile plastic deformation mechanism of the sample at low temperature is dominated by dislocation slip. However, the tensile plastic deformation mechanism at high temperature shows that not only the dislocation slip mechanism but also the twinning mechanism play a paramount role [20]. This difference can also be confirmed by the ODF figures obtained by Figures 3 and 7 . The textures of the deformation areas of the tensile samples at $400{ }^{\circ} \mathrm{C}$ are quite different from those at $600^{\circ} \mathrm{C}$, as shown in Figures 7 and 8 . It can be seen in the ODF figures obtained in the deformation areas of sample tensile at different temperatures that very high densities of texture components of $\{110\}<112>$ and $\{112\}<111>$ are formed at $100{ }^{\circ} \mathrm{C}$ to $400{ }^{\circ} \mathrm{C}$, which corresponds to dislocation slips. However, the texture components of $\{111\}<110>,\{011\}<3-11>$, and $\{011\}<100>$ are found at $600{ }^{\circ} \mathrm{C}$ to $800{ }^{\circ} \mathrm{C}$, suggesting the formation of deformation twins, as shown in Figure 2. The occurrence of deformation twins according to the texture variations, proves that the precipitate phase formed at $600{ }^{\circ} \mathrm{C}$ hinders the slip of the dislocations.

\subsection{Strengthening Mechanisms of the Ni48W35Co17 Alloy}

The strength of an alloy is considered to be the combined effect of multiple strengthening mechanisms, i.e., solid solution strengthening, grain boundary strengthening, precipitation strengthening, and work hardening mechanisms [21-23]. The strength of the $\mathrm{Ni}_{48} \mathrm{~W}_{35} \mathrm{Co}_{17}$ alloy continuously decreases as the temperature increases, which has been observed in previous studies.

It can be seen from the mechanical properties obtained in this study (as seen in Figure 1) that the variation in yield strength obeys an exponential relationship, according to the Aframi equation. Therefore, the variation in the yield strength of this alloy can be expressed by Equation (1), which is obtained by fitting the experimental data shown in Figure 9. A very good fitting to the experimental data is found described by Equation (1), which is very feasible. Another thing that should be noted is that the yield strength is reduced very quickly in the temperature range from $100{ }^{\circ} \mathrm{C}$ to $400{ }^{\circ} \mathrm{C}$ but it is slower in the 
temperature range from $400{ }^{\circ} \mathrm{C}$ to $800{ }^{\circ} \mathrm{C}$, which is confirmed by both the experimental results and Equation (1):

$$
\sigma=348.2-165.2 * \exp (-304.1 / \mathrm{T})
$$
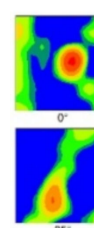

19
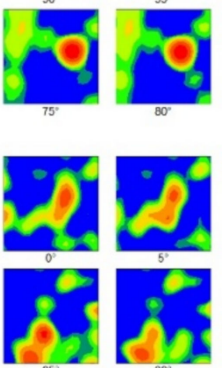

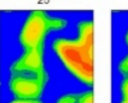
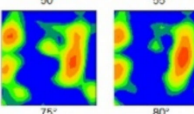
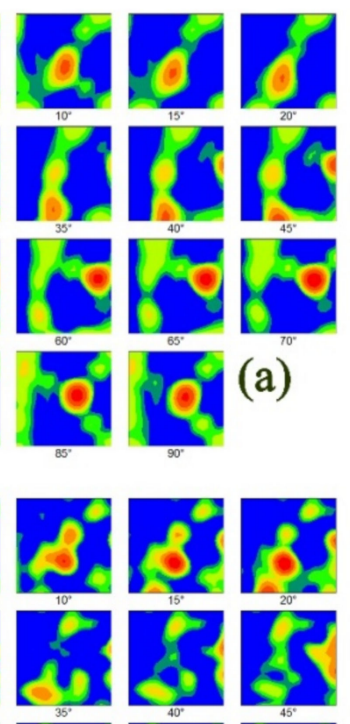

(a)
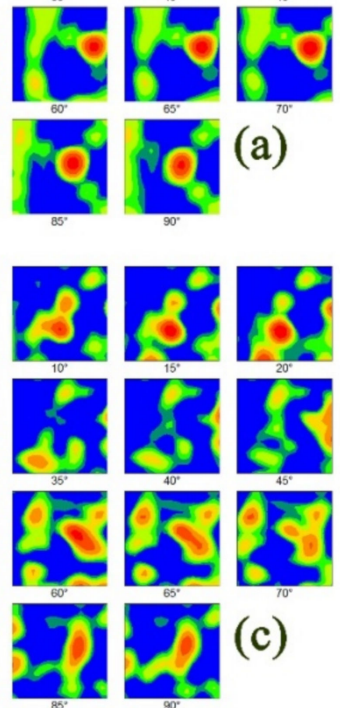

(c)
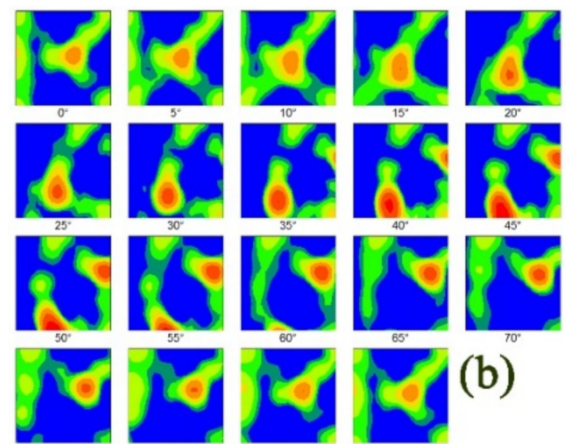

(b)
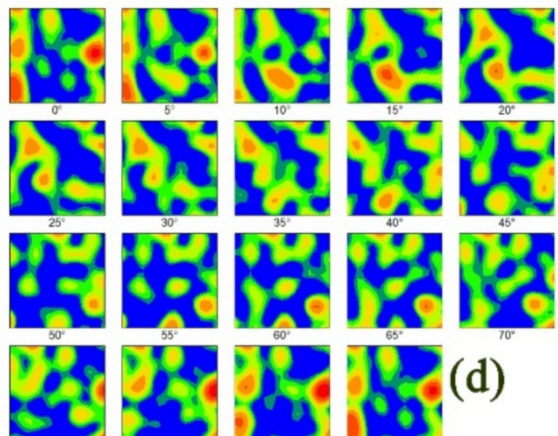

Figure 7. The ODF figures of the deformation areas of the samples tensiled at different temperatures: (a) $100{ }^{\circ} \mathrm{C}$, (b) $400{ }^{\circ} \mathrm{C}$, (c) $600{ }^{\circ} \mathrm{C}$, and (d) $800^{\circ} \mathrm{C}$.

(a)

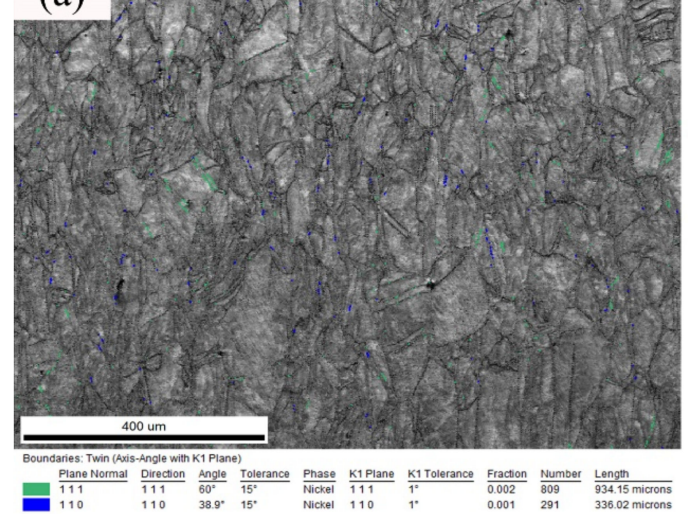

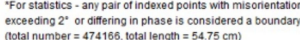

(b)

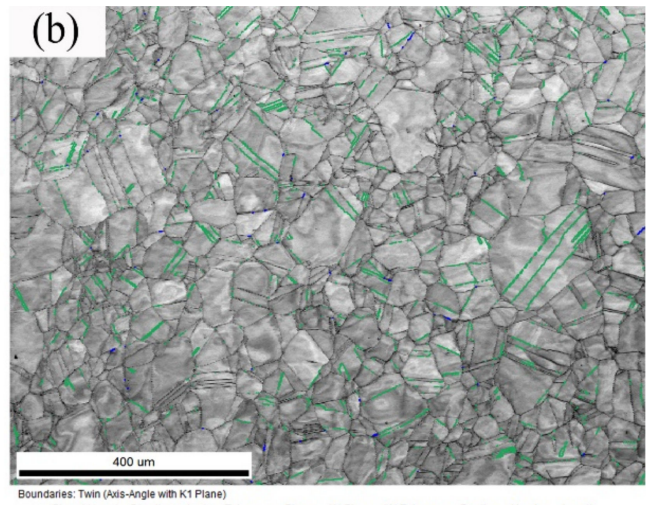

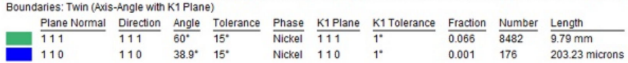

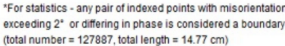

Figure 8. SEM micrographs of samples obtained by stretching at different temperatures (a) $400{ }^{\circ} \mathrm{C}$, (b) $600{ }^{\circ} \mathrm{C}$. 


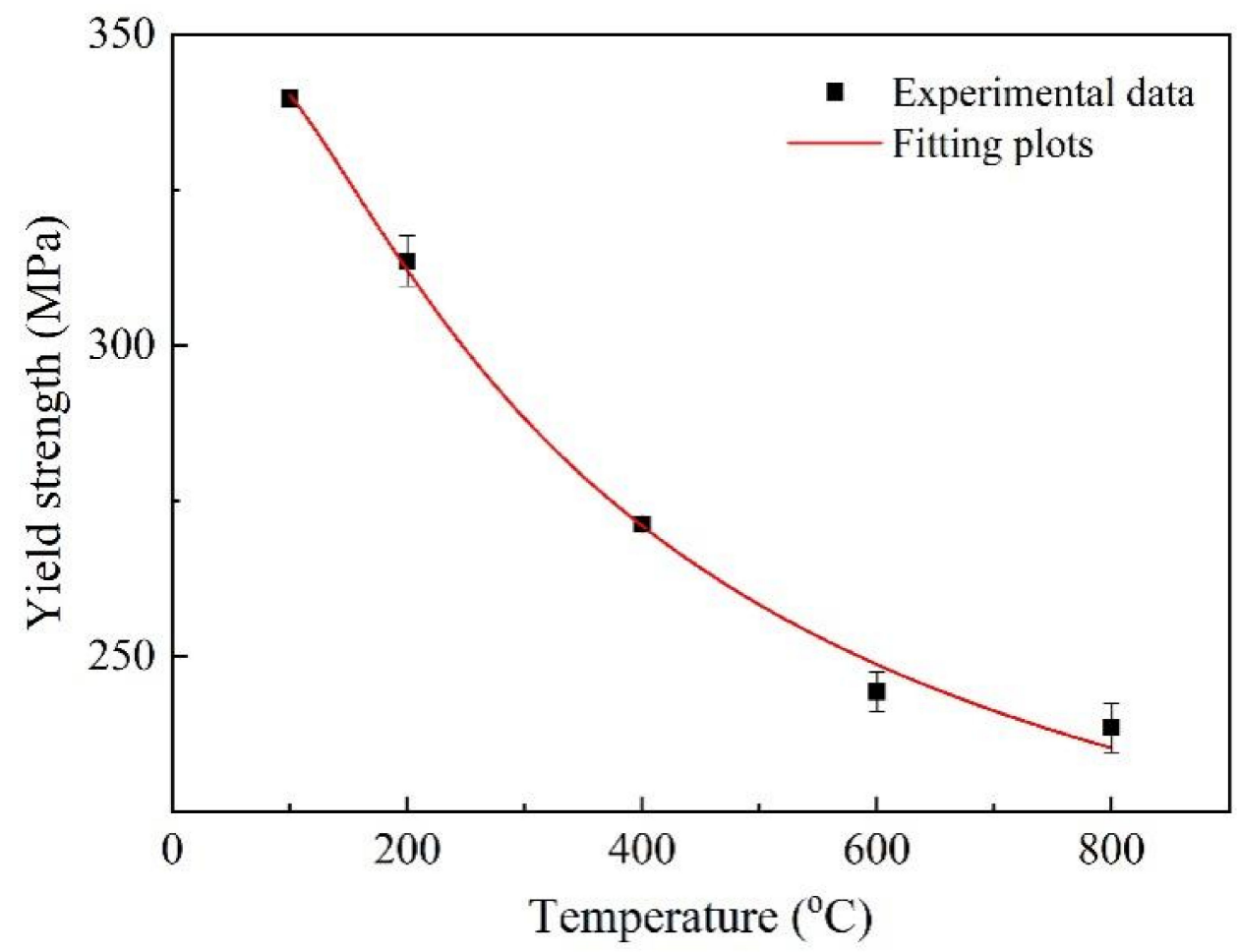

Figure 9. The experimental and fitting results of yield strength with increasing temperatures.

Therefore, it is reasonable to believe that the strengthening mechanism of the alloy is different at different temperatures. No obvious precipitation is observed in the sample at $400{ }^{\circ} \mathrm{C}$. The strengthening of the alloy mainly depends on the solid solution and grain boundary strengthening. It has been reported [24] that the soft glide plane effect can be caused by the formation of short-range ordered phases. Therefore, the dislocation slip inside the grains can be improved by this softening effect. However, the distribution and amount of the NiW precipitates is quite different from the situations concerning the precipitation hardening. The deformation will be limited since the short-range ordered lattice may be broken by the movement of dislocations. The cross-slip of dislocations is consequently hindered by the formation and transformation of these ordered precipitates. These precipitates are only found in the grain boundaries with very small size. The precipitates can be considered as some brittle points in the grain boundaries, which may cause the formation of internal micro-cracks during tensile. Therefore, the precipitation hardening effect is also limited.

Combining the above analysis, the strengthening of the alloy mainly depends on the solid solution, grain boundaries, and precipitation strengthening. Precipitation strengthening is mainly due to hindering the movement of dislocations, the mechanisms of which are mainly divided into two types, namely, the Orowan mechanism (bypassing) and the cutting mechanism $[25,26]$. The sizes of the NiW phases are approximately $5 \mathrm{~nm}$. Therefore, the cutting mechanism is probably the main strengthening mechanism of these small NiW precipitates. Thus, the sample will be strengthened by the NiW precipitates in the form of dislocations cutting.

The NiW phase strengthening effect is poor, thereby limiting the contribution of precipitation strengthening. In addition, precipitation causes the concentration of solute atoms to decrease, and the solid solution strengthening effect weakens. The high temperature causes the matrix grains to grow, the matrix softens, and the effect of grain boundary strengthening also dramatically weakens. Finally, the strength of the alloy decreases at high temperatures. 


\section{Conclusions}

In this study, the high-temperature mechanical properties and strengthening mechanism of a Ni48W35Co17 alloy were investigated. The following conclusions can be drawn from this study:

(1) The strength of the Ni48W35Co17 alloy decreases as the temperature increases, obeying an exponential relationship. An abnormal decrease in elongations at temperatures from $400{ }^{\circ} \mathrm{C}$ to $800{ }^{\circ} \mathrm{C}$ is found in this alloy. The tensile strength of the alloy is $471 \mathrm{MPa}$ at $600{ }^{\circ} \mathrm{C}$, which is $38 \%$ lower than that at $400{ }^{\circ} \mathrm{C}$. The elongation rate of the alloy is $19 \%$ at $600{ }^{\circ} \mathrm{C}$, which is $72 \%$ lower than that at $400{ }^{\circ} \mathrm{C}$.

(2) Numerous tiny precipitates can be found at $600{ }^{\circ} \mathrm{C}$, which might be the reason for the decrease in the plasticity of the alloy. The structure of the NiW phase is orthogonal, and the orientation relationship between the matrix and NiW phase is $(200)_{\mathrm{Ni}} / /(240)_{\mathrm{NiW}}$ and [001]Ni//[001]NiW. The cross-slip of dislocations is consequently hindered by the formation and transformation of these ordered precipitates.

(3) The tensile plastic deformation mechanism of the sample at low temperature is dominated by dislocation slip, whereas the tensile plastic deformation mechanism at high temperature shows that not only the dislocation slip mechanism but also the twinning mechanism plays a paramount role. The strengthening of the alloy at $600{ }^{\circ} \mathrm{C}$ mainly depends on the solid solution, grain boundary, and precipitation strengthening.

Author Contributions: Conceptualization, G.X.; methodology, G.X., W.X. and R.W.; software, Y.F.; validation, G.X., W.X.; formal analysis, G.X., W.X. and L.Z.; investigation, W.X.; resources, G.X., L.Z.; data curation, G.X., W.X., Y.F., K.F. and R.W.; writing—original draft preparation, G.X.; writingreview and editing, Y.F., K.F. and L.Z.; visualization, G.X., W.X.; supervision, G.X. and L.Z.; project administration, G.X.; funding acquisition, G.X. and L.Z. All authors have read and agreed to the published version of the manuscript.

Funding: This work was supported by Youth Foundation of National Natural Science Foundation China (grant numbers 52001020) and Fundamental Research Funds for the Central Universities (FRF-IDRY-19-012).

Data Availability Statement: Data is contained within the article.

Conflicts of Interest: The authors declare no conflict of interest.

\section{References}

1. Levin, Z.S.; Hartwig, K.T. Hardness and microstructure of tungsten heavy alloy subjected to severe plastic deformation and post-processing heat treatment. Mater. Sci. Eng. A 2015, 635, 94-101. [CrossRef]

2. $\mathrm{Hu}, \mathrm{K} . ; \mathrm{Li}, \mathrm{X} . ; \mathrm{Ai}, \mathrm{X}$; $\mathrm{Qu}, \mathrm{S}$; $\mathrm{Li}$, Y. Fabrication, characterization, and mechanical properties of 93W-4. 9Ni-2. 1Fe/95W-2. 8Ni-1. $2 \mathrm{Fe}-1 \mathrm{Al}_{2} \mathrm{O}_{3}$ heavy alloy composites. Mater. Sci. Eng. A 2015, 636, 452-458. [CrossRef]

3. Xu, Z.; Huang, F. Thermomechanical behavior and constitutive modeling of tungsten-based composite over wide temperature and strain rate ranges. Int. J. Plast. 2013, 40, 163-184. [CrossRef]

4. $\quad \mathrm{Li}, \mathrm{Y} . ; \mathrm{Hu}, \mathrm{K}$.; $\mathrm{Li}, \mathrm{X}$.; $\mathrm{Ai}, \mathrm{X} . ; \mathrm{Qu}$, S. Fine-grained 93W-5.6Ni-1.4Fe heavy alloys with enhanced performance prepared by spark plasma sintering. Mater. Sci. Eng. A 2013, 573, 245-252. [CrossRef]

5. Li, Y.; Liu, G.Q.; Hu, X.B.; Wu, L.H.; Tan, C.W.; Dravid, V.P.; Liu, S.Z. A novel medium heavy alloy (MHA) with excellent static/dynamic properties and impact toughness. Scr. Mater. 2019, 162, 311-315. [CrossRef]

6. Hu, D.Y.; Meng, K.P.; Jiang, H.L. Experimental Investigation of Dynamic Properties of AerMet 100 Steel. Procedia Eng. 2015, 99, 1459-1464. [CrossRef]

7. Shi, X.; Zeng, W.; Zhao, Q.; Peng, W.; Kang, C. Study on the microstructure and mechanical properties of Aermet 100 steel at the tempering temperature around $482{ }^{\circ} \mathrm{C}$. J. Alloy. Compd. 2016, 679, 184-190. [CrossRef]

8. Yadav, S.; Ramesh, K.T. The mechanical properties of tungsten-based composites at very high strain rates. Mater. Sci. Eng. A 1995, 203, 140-153. [CrossRef]

9. Lee, W.S.; Su, T.T. Mechanical properties and microstructural features of AISI 4340 high-strength alloy steel under quenched and tempered conditions. J. Mater. Process. Technol. 1999, 87, 198-206. [CrossRef]

10. Lai, G.Y.; Wood, W.E.; Clark, R.A.; Zackay, V.F.; Parker, E.R. The effect of austenitizing temperature on the microstructure and mechanical properties of as-quenched 4340 steel. Metall. Mater. Trans. B 1974, 5, 1663-1670. [CrossRef] 
11. Humail, I.S.; Akhtar, F.; Askari, S.J.; Tufail, M.; Qu, X. Tensile behavior change depending on the varying tungsten content of W-Ni-Fe alloys. Int. J. Refract. Met. Hard Mater. 2007, 25, 380-385. [CrossRef]

12. Gero, R.; Borukhin, L.; Pikus, I. Some structural effects of plastic deformation on tungsten heavy metal alloys. Mater. Sci. Eng. A 2001, 302, 162-167. [CrossRef]

13. Ye, T.; Yi, J.; Li, L.; Peng, Y.; Lu, Y.; Hu, L. New Advances in Study of Tungsten Heavy Alloys. Mater. Rev. 2003, 17, 15-18.

14. Ravi Kiran, U.; Panchal, A.; Sankaranarayana, M.; Nageswara Rao, G.V.S.; Nandy, T.K. Effect of alloying addition and microstructural parameters on mechanical properties of 93\% tungsten heavy alloys. Mater. Sci. Eng. A 2015, 640, 82-90. [CrossRef]

15. Liu, G.Q.; Wang, C.X.; Liu, S.Z.; Li, Y.; Tan, C.W.; Liu, Z.C. Effect of aging treatment on microstructure and properties of NiW750 high-density alloy. Mater. Sci. Technol. 2019, 27, 36-43.

16. German, R.M.; Bourguignon, L.L.; Rabin, B.H. Microstructure Limitations of High Tungsten Content Heavy Alloys. Phys. Metall. Mater. 1985, 37, 36-39. [CrossRef]

17. Liu, Z.; Nie, Z.; Ning, X.; Zhao, X.; Yu, X.; Wang, F.; Tan, C. Mechanical response and microstructural evolution of Ni-27 W alloys during uniaxial tension. J. Alloys Compd. 2021, 891, 161972.

18. Das, J.; Kiran, U.R.; Chakraborty, A.; Prasad, N.E. Hardness and tensile properties of tungsten based heavy alloys prepared by liquid phase sintering technique. Int. J. Refract. Met. Hard Mater. 2009, 27, 577-583. [CrossRef]

19. Ding, L.; Xiang, D.P.; Li, Y.Y.; Zhao, Y.W.; Li, J.B. Phase, microstructure and properties evolution of fine-grained W-Mo-Ni-Fe alloy during spark plasma sintering. Mater. Des. 2012, 37, 8-12. [CrossRef]

20. Das, J.; Sarkar, R.; Rao, G.A.; Sankaranarayana, M.; Nandy, T.K.; Pabi, S.K. Flow behaviour of a heat treated tungsten heavy alloy. Mater. Sci. Eng. A 2012, 553, 119-127. [CrossRef]

21. Starink, M.J.; Wang, S.C. A model for the yield strength of overaged Al-Zn-Mg-Cu alloys. Acta Mater. 2003, 51, 5131-5150. [CrossRef]

22. Zhang, X.; Godfrey, A.; Huang, X.; Hansen, N.; Liu, Q. Microstructure and strengthening mechanisms in cold-drawn pearlitic steel wire. Acta Mater. 2011, 59, 3422-3430. [CrossRef]

23. Chihiro, W.; Satoshi, T.; Ryoichi, M. Effects of Small Addition of Ti on Strength and Microstructure of a Cu-Ni-Si Alloy. Metall. Mater. Trans. A 2015, 46, 2469-2475.

24. Goodchild, D.; Roberts, W.T.; Wilson, D.V. Plastic deformation and phase transformation in textured austenitic stainless steel. Acta Metall. 1970, 18, 1137-1145. [CrossRef]

25. Mabuchi, M.; Higashi, K. Strengthening mechanisms of Mg-Si alloys. Acta Mater. 1996, 44, 4611-4618. [CrossRef]

26. Lee, J.; Jung, J.Y.; Lee, E.S.; Park, W.J.; Ahn, S.; Kim, N.J. Microstructure and properties of titanium boride dispersed Cu alloys fabricated by spray forming. Mater. Sci. Eng. 2000, 277, 274-283. [CrossRef] 